\title{
Françoise Gollain, leitora de André Gorz
}

GOLLAIN, Françoise. André Gorz : une philosophie de l'émancipation. Paris: L'Harmattan, 2018. 334 p.

\section{Nuno Miguel Cardoso Machado*}

\section{Resumo}

Esta resenha leva a cabo uma súmula e uma apreciação crítica da obra André Gorz: une philosophie de l'émancipation, assinada pela socióloga francesa Françoise Gollain. Trata-se de uma biografia intelectual de Gorz (1923-2007) que expõe cronologicamente e com elevado grau de minúcia a trajetória do seu pensamento ao longo de seis décadas de compromisso com a filosofia crítica. Recorrendo a todas as publicações de Gorz, assim como a manuscritos inéditos e à sua correspondência, Gollain dá conta das múltiplas inflexões da teoria gorziana. Desse modo, contribui decisivamente para superar a receção académica monolítica de André Gorz: a literatura secundária tende a centrar-se (quase) exclusivamente nos escritos tardios inaugurados com a redação de Adeus ao proletariado (1980). Um dos aspetos mais importantes da sua (re)interpretação é a tese de que a filosofia existencialista sartreana constitui o fundamento transversal à produção bibliográfica gorziana na sua inteireza. Em Gorz, a luta do sujeito contra a alienação em nome da liberdade é omnipresente. Apesar de uma ou outra falha menor, André Gorz: une philosophie de l'émancipation é uma das melhores biografias intelectuais do autor.

Palavras-chave: Gorz, Gollain, emancipação, existencialismo, biografia intelectual.

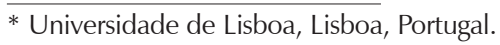




\section{Françoise Gollain, reader of André Gorz}

\section{Abstract}

This review undertakes a summary and a critical assessment of the work André Gorz: une philosophie de l'émancipation, authored by the French sociologist Françoise Gollain. It is an intellectual biography of Gorz (1923-2007) that presents chronologically and with great detail the trajectory of his thought throughout six decades of engagement with critical philosophy. Analyzing all of Gorz's publications, as well as unpublished manuscripts and his correspondence, Gollain gives an account of the multiple inflections of gorzian theory. Thus, a decisive contribution is made to overcome the monolithic academic reception of André Gorz: the secondary literature tends to focus (almost) exclusively in the late writings that followed the publication of Farewell to the working class (1980). One of the most important aspects of Gollain's (re)interpretation is the thesis that the sartrean existentialist philosophy constitutes the foundation that cuts across Gorz's bibliographical output in its entirety. In Gorz, the struggle of the subject against alienation in the name of freedom is omnipresent. Despite a couple of minor flaws, André Gorz: une philosophie de l'émancipation represents one of the best intellectual biographies of this thinker.

Keywords: Gorz, Gollain, emancipation, existentialism, intellectual biography.

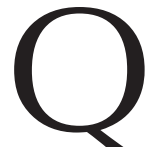

uando se fala de André Gorz (1923-2007) pensa-se imediatamente num dos teóricos-chave na discussão sociológica em torno da crise da "sociedade do trabalho". De fato, a atenção da literatura secundaria centra-se (quase) exclusivamente nos seus escritos tardios, inaugurados com a publicação de Adeus ao proletariado em 1980. Perdese, assim, de vista as especificidades de um percurso intelectual complexo marcado por várias inflexões, nomeadamente: a sua importância no desenvolvimento da filosofia existencialista na década de 1950, o seu estatuto de figura nuclear da Nova Esquerda na década de 1960 e o seu papel decisivo na eclosão da denominada ecologia política na década de 1970.

O predomínio dessa abordagem redutora ao pensamento de André Gorz constituiu um contexto desfavorável à redação de biografias intelectuais do autor. Estas contavam-se, até agora, pelos dedos de uma mão. Adrian 
Little (2013 [1996]) deu o sinal de partida com The political thought of André Gorz. Seguiu-se André Gorz: a critical introduction, de Conrad Lodziak e Jeremy Tatman (1997), e André Gorz and the sartrean legacy: arguments for a person-centred social theory, de Finn Bowring (2000). Apesar do inegável mérito precursor, todas essas pesquisas padecem de lacunas relevantes. A obra de Little ignora misteriosamente os três livros e as dezenas de ensaios de cunho existencialista, ou seja, a parcela fundadora do corpus gorziano. Por sua vez, a extrema concisão da obra de Lodziak e Tatman acarreta inevitavelmente um certo grau de superficialidade. Finalmente, o livro de Bowring é o inverso simétrico daquele de Little, porquanto a ênfase excessiva nos trabalhos gorzianos dos anos 50 implica uma menor atenção dedicada aos escritos posteriores.

No novo milénio, a situação melhora significativamente em termos qualitativos. Em André Gorz: trabalho e política, Josué Pereira da Silva (2002) oferece uma análise primorosa e detalhada da trajetória intelectual de Gorz. Porém, conforme se depreende da data de publicação, o autor não examina os escritos gorzianos cruciais redigidos nos derradeiros cinco anos de vida. ${ }^{1}$ Catorze anos volvidos, Willy Gianinazzi (2016) coloca nos escaparates a obra magistral intitulada André Gorz: une vie, onde escalpeliza a evolução do pensamento gorziano ao longo de sessenta anos de compromisso com a teoria crítica e lança luz sobre inúmeros aspetos da sua vida pessoal.

Chegou, finalmente, a altura de apresentar a personagem principal desta resenha. Depois de Une critique du travail (Gollain, 2000) fortemente inspirada pelas teses de Gorz, do breve ensaio André Gorz: pour une pensée de l'écosocialisme (Gollain, 2014) e de dezenas de artigos científicos profícuos sobre o autor austríaco radicado em França (por exemplo, Gollain, 2008, 2009, 2010, 2012, 2015, 2017), Françoise Gollain publicou agora uma biografia intelectual que a consagra definitivamente como uma das principais especialistas no pensamento gorziano à escala global. Amiga íntima de Gorz, Gollain pôde apelar às memórias de longas conversas

$1 \mathrm{O}$ autor colmata posteriormente esta lacuna com a publicação de vários artigos (Silva, 2009, 2010, 2014, 2017a, 2017b). 
teórico-filosóficas. Ademais, acedeu aos fundos de André Gorz depositados no Institut Mémoires de l'Édition Contemporaine e, assim, conseguiu consultar numerosos manuscritos inéditos e estudar minuciosamente a correspondência de Gorz.

Em André Gorz: une philosophie de l'émancipation, Gollain adota um método de exposição cronológico. Na 1a Parte, a autora examina detalhadamente os textos gorzianos dos anos 50, porque considera que estes constituem "a premissa filosófica onde assentará a abordagem crítica de André Gorz na sua totalidade durante meio século" (p. 41). Jean-Paul Sartre era "a referência intelectual incontornável dessa época" (p. 23). $\mathrm{O}$ "jovem Gorz" não foge à regra e fica bastante impressionado com a "teorização sartriana da liberdade" apresentada em O ser e o nada (p. 27).

A "centralidade do sujeito", em Gorz, decorre justamente daquele que perceciona ser o "caráter inacabado (inachevée) da liberdade" na sociedade contemporânea (p. 38). De acordo com a perspetiva existencialista advogada, "a alienação apenas pode ser minada pela exigência de um sentido (sens) para e por meio do sujeito, ator da sua história" (p. 29, itálico no original). Em Fundamentos para uma moral (1955), o seu primeiro livro, Gorz propõe-se, então, "produzir uma ontologia suscetível de fundamentar uma moral, recenseando e hierarquizando os valores" humanos nucleares (p. 29). O autor conclui, em linha com as proposições de Sartre, que "a liberdade constitui o valor supremo, o fundamento de todos os outros valores" (p. 29).

De cariz assumidamente autobiográfico, O traidor (1958) versa sobre as "condições familiares, sociais, históricas" que afetam "as escolhas axiológicas fundamentais" e afastam o indivíduo da "autonomia" (p. 41). Ao longo do livro torna-se evidente que as preocupações esboçadas em Fundamentos estão enraizadas nas dificuldades existenciais e identitárias vivenciadas pelo jovem Gorz. Nascido em 1923 na cidade de Viena, o autor experimentou em primeira mão as dificuldades de ter um "pai judeu" e uma "mãe católica" num período histórico tão conturbado (p. 44). Gorz "sofria por (...) não conseguir corresponder" às "expetativas" de uma 
mãe austera e por ser um alvo do "antissemitismo" galopante (p. 45). Aos 16 anos, é enviado para um colégio na Suíça, de maneira que o "exílio" forçado "amplificará o exílio interior pré-existente" (p. 45). Essa bagagem emocional pesada será transportada para a vida adulta. Conforme explica Gollain, "aos 32 anos ele ainda se sentia (...) essencialmente incapaz de viver" (p. 41, itálico no original).

Vítima de uma "solidão radical", a descoberta dos escritos de Sartre permite-lhe "dar um sentido ao seu próprio desespero e à sua angústia" (p. 42). Gollain fala de um "laço intrínseco entre o existencialismo adotado por Gorz como perspetiva teórica e, por outro lado, como método de análise da sua própria vida" (p. 41-42). Com efeito, O traidor "rastreia o caminho que o conduz à autenticidade, seguindo o método de conversão moral (...) elaborado por Sartre"; ou seja, trata-se de um exercício de "psicanálise existencial" (p. 44). Em retrospetiva, Gorz percebe que o seu isolamento foi quebrado graças à relação com Doreen Keir, sua futura esposa, com quem emigra para Paris em 1949 (p. 46 e 50), à adoção da profissão de jornalista (p. 50) e à aceitação da faceta de "escritor-filósofo comprometido" como meio de realização pessoal e de inserção social (p. 49).

Gollain sustenta que A moral da história (1959) foi bastante influenciada pelo "existencialismo marxista" exposto por Sartre em Crítica da razão dialética (p. 24). Nesse livro, Gorz desloca o seu foco da alienação individual para a alienação entendida como "fenômeno econômico e social" (p. 58). Recorrendo à noção sartriana de "prático-inerte" (p. 59), Gorz defende que a alienação resulta da subordinação do trabalho aos ditames do "capital" (p. 60). Ao inscrever-se na "matéria" (p. 67), a "práxis" humana "petrificada" confronta os indivíduos como uma "exigência tirânica" (p. 68).

Gorz continua a postular uma "conceção do sujeito como indivíduo" potencialmente "autônomo" (p. 36). Desse modo, "ainda que condicionada, sua práxis não é determinada (...) em todos os seus detalhes" (p. 57). Porém, para o sujeito "ser livre" já não basta um processo de conversão moral, sendo requerida nada menos do que a superação do "capitalismo" (p. 56). Gorz elege o "proletariado" como agente emancipatório latente 
(p. 64). Urge salientar, no entanto, que, na sua perspetiva, "o comunismo (...) representa uma 'necessidade facultativa'", ou seja, "ninguém pode ser constrangido a libertar-se" (p. 62).

Na 2a Parte, Françoise Gollain analisa os escritos gorzianos das décadas de 1960 e 1970. Num período marcado pela ascensão meteórica do "estruturalismo" (p. 82) e, depois, do pós-estruturalismo, Gorz permanece um dos principais defensores da "filosofia existencialista" (p. 84). Em paralelo, Gorz descobre "uma nova fonte de inspiração nos (...) pensadores italianos" associados ao operaismo (p. 81). Isso é patente em Estratégia operária e neocapitalismo (1964) e O socialismo difícil (1968). Contrariando "o terceiro-mundismo predominante na Nova Esquerda" (p. 115), Gorz continua a apostar as suas fichas na "classe operária" dos países capitalistas avançados como sujeito emancipatório privilegiado (p. 91).

De fato, na óptica do autor, os événements de Maio de 1968 testemunham a eclosão de "novas necessidades" totalmente "incompatíveis" com a "lógica" mercantil capitalista (p. 93, itálico no original). Assiste-se à deslocação das reivindicações do plano quantitativo para o plano qualitativo": as pessoas anseiam por um modo de vida distinto (p. 95). Nesse âmbito, Gorz considera que o "controle operário" (p. 101), quer dizer, a "autogestão", é a chave não apenas para a transição revolucionária como, também, para a organização de uma "sociedade (...) socialista" (p. 102).

É digno de nota que, ao longo dos anos 60, Gorz ainda não identifica "a crise profunda (...) do assalariamento" (p. 103), nem preconiza a superação do trabalho. Na perspectiva do autor, verifica-se, tão-somente, "uma contradição entre a essência ativa e potencialmente criadora do trabalho (...) e o estatuto passivo de mercadoria ao serviço do lucro que lhe é atribuído pelo sistema capitalista" (p. 99). Assim, o socialismo consiste na "emancipação dos trabalhadores (...) no seio do trabalho através da otimização das condições laborais" (p. 103, itálico no original) e da apropriação dos meios de produção. 
Em 1973, Gorz organiza a coletânea Crítica da divisão do trabalho, onde assina o prefácio e um capítulo (p. 117). Nestes ensaios e, posteriormente, em Ecologia e política (1975), verifica-se uma inflexão no pensamento de Gorz. Opondo-se a grande parte da "tradição marxista" e à sua própria posição nos anos 60 , o autor sustenta que as "forças produtivas" não são neutras (p. 121), nem facilitam, por isso, necessariamente, a autonomia dos indivíduos (p. 124). De fato, tanto a "ciência" como a "tecnologia" modernas são "instrumentalizadas pela lógica do capitalismo" (p. 121). Com o advento da grande indústria emerge o "despotismo de fábrica", de maneira que "as técnicas são sempre (...) meios de dominar, disciplinar e militarizar o trabalho operário" (p. 118).

Nesse sentido, a "apropriação" coletiva de forças produtivas que "servem os interesses do capital" é pura e simplesmente "impossível" (p. 126). Fortemente inspirado pelas obras de Ivan Illich, Gorz defenderá, ao longo da década de 1970, a urgência de uma profunda "mudança tecnológica" em que o "gigantismo" maquinal opressivo (p. 124) ceda lugar a ferramentas conviviais de menor dimensão, passíveis de serem geridas autonomamente pelos utilizadores (p. 142).

Conforme indica o título, Ecologia e política assinala também o compromisso precursor de Gorz com o eco-socialismo (p. 141). Na óptica do autor, "a componente ambiental (...) não é suficiente (...) para definir a ecologia" (p. 131), pois o ambientalismo já foi cooptado pela sociedade burguesa (p. 140). Assim, a ecologia, na aceção gorziana, constitui "uma abordagem intrinsecamente política capaz de esboçar um outro projeto de civilização" (p. 131). O eco-socialismo "pressupõe uma rutura com a racionalidade econômica" mercantil (p. 141) assente na "delapidação dos recursos" naturais "limitados" (p. 136). O "crescimento econômico indefinido", i.e., a acumulação de capital, é uma ameaça para o planeta Terra e para as espécies que nele habitam, pelo que a produção material tem de ser reduzida substancialmente à escala global (p. 136 e 141). Gorz crê ser possível viver melhor consumindo menos. 
Françoise Gollain dedica a $3^{\underline{a}}$ e a $4^{\underline{a}}$ Partes da sua obra ao estudo do pensamento gorziano da década de 1980. Adeus ao proletariado (1980), Os caminhos do paraíso (1983) e Metamorfoses do trabalho (1988) representam una enorme "viragem" na teoria do autor (p. 147). Gorz defende a "tese" radical da "historicidade do trabalho": trata-se de uma categoria exclusivamente moderna, inextrincável da (ir)racionalidade mercantil e do seu princípio da maximização (p. 225). As sociedades pré-capitalistas, por seu turno, obedeciam ao princípio da suficiência no seio de um "modo de vida regido por tradições que desafiavam a racionalidade econômica" ( $p$. 225, itálico no original). Nesse contexto, "as necessidades essenciais eram satisfeitas pela autoprodução no quadro da comunidade doméstica e aldeã por meio de uma diversidade de atividades de subsistência que não eram avaliadas nem trocadas" (p. 226).

Conforme "a produção e o consumo mercantis" vão perdendo "o seu caráter marginal" (p. 226), surge então uma nova categoria (re)produtiva social universal: o "trabalho 'abstrato'" (p. 227) de cariz "heterônomo" (p. 157). Este "devém uma grandeza quantificável, (...) um dispêndio de energia mensurável, intercambiável com qualquer outra, tornando igualmente os 'trabalhadores' intercambiáveis" (p. 227). Está-se perante uma forma de prática "subordinada ao imperativo da valorização" (p. 229), ou seja, "uma produção guiada pela racionalidade econômica, porque se destina à troca no mercado onde se encontram em concorrência produtores (...) sem laços entre si" (p. 227).

Inspirado explicitamente em Karl Polanyi, Gorz sustenta que "a economia de mercado assinala a autonomização dessa forma" inaudita de "racionalidade" mercantil "face às exigências e aos controlos da sociedade" (p. 192). Tanto a "produção" capitalista como o "aparelho administrativo" burocrático encerram uma forma de dominação impessoal, quer dizer, "a lei do capital é efetivada por um poder (...) sem sujeito (...) funcional" (p. 182, itálico no original). Portanto, o capitalista não passa de um funcionário do capital. Por sua vez, o operário "encontra-se subsumido no processo 
global" da valorização (p. 155) e, assim, é "estruturalmente homogéneo face ao capital" (p. 158). Capital e trabalho são as duas faces da mesma moeda.

Tal como salienta Gollain, Gorz identifica igualmente a crise do modo de (re)produção burguês. A "degradação da taxa de lucro" é provocada pela "substituição" do "trabalho" operário pela maquinaria (capital fixo), isto é, pela "subida da composição orgânica do capital" (p. 163). Na sequência da 3a Revolução Industrial e da disseminação concomitante da "automação", impelida inadvertidamente pela concorrência, o trabalho vivo empregado começa a contrair-se em termos absolutos (p. 164). Como só o trabalho abstrato produz mais-valia, a revolução microeletrônica impede, por sua própria natureza, a constituição de "um novo ciclo longo de acumulação" sustentado (p. 164).

Gollain assinala, ainda, outro dos aspetos-chave do pensamento gorziano dessa fase: uma vez que o trabalho é irremediavelmente heterônomo e se encontra em crise, a emancipação não pode consistir em libertar o trabalho, mas em libertar-se do trabalho (p. 148). Nesse sentido, o autor "abandona definitivamente a crença numa missão histórica da classe operária" ( $p$. 153) - o sujeito suporte do trabalho e, portanto, a "imagem invertida do capital" (p. 158). A "superação" prática "do capitalismo em nome de uma racionalidade diferente terá de ser realizada por um novo sujeito" revolucionário, que Gorz designa por "não-classe de não-trabalhadores" (p. 159). A não-classe "põe-se como sujeito através da recusa do trabalho social" abstrato, mediante a "negação" de uma atividade percebida como alienada (p. 159). Ela é composta pelos “'supranumerários' resultantes do processo de abolição do trabalho pela informatização" (p. 160), ou seja, pelos "desempregados efetivos ou potenciais" (p. 162).

O esquema utópico de Gorz consiste agora na proposta de uma sociedade dual assente na "dicotomia heteronomia-autonomia" (p. 175). A esfera autônoma é o locus da "soberania individual subtraída à racionalidade econômica" (p. 175); nela, as práticas "contêm em si mesmas a sua própria finalidade" (p. 176) e têm em vista a autorrealização dos seres humanos. Gorz, 
ressalva Gollain, defende que, "ao contrário das mega-tecnologias do período industrialista, (...) a microeletrônica (...) é uma tecnologia de charneira", visto que "não interdita nem impõe nenhum tipo de desenvolvimento" (p. 167). Por outras palavras, a informática pode ser aplicada a tecnologias produtivas conviviais - no sentido illichiano do termo - em pequena escala, e, desse modo, permitir tanto a "autogestão" descentralizada (p. 168) como a "autoprodução" individual e comunitária (p. 166).

Por sua vez, a esfera heterônoma é o locus da "racionalidade econômica" residual (p. 196) onde se permite o funcionamento livre dos "mecanismos de mercado" (p. 192). A finalidade desse domínio societal é "produzir, da maneira mais eficaz tecnicamente, os bens e serviços necessários destinados à expansão da esfera autônoma", mas que "extravasam as possibilidades de uma comunidade limitada" (p. 175). O objetivo de Gorz é, graças à difusão da automação, reduzir enormemente o tempo dedicado ao trabalho na esfera heterônoma e, consequentemente, aumentar o tempo disponível para as atividades autônomas. O emprego "assalariado" cessará de ser a "atividade principal" dos indivíduos (p. 165) numa "sociedade do tempo libertado" onde o "maior desenvolvimento" pessoal ocorre justamente "fora do trabalho" (p. 165, itálico no original). ${ }^{2}$ Dado que o tempo de trabalho deixa paulatinamente de ser a medida da riqueza criada, "o direito a um rendimento não pode estar subordinado à posse de um emprego", pelo que Gorz reivindica um "rendimento social garantido" (p. 164).

Finalmente, na 5a parte do livro, Françoise Gollain analisa o pensamento gorziano das décadas de 1990 e 2000. Até meados dos anos 90 Gorz limita-se a reafirmar as proposições-chave avançadas nos escritos pretéritos. Todavia, em Misérias do presente, riqueza do possível (1997) e, sobretudo, em O imaterial (2003), é patente a influência da "corrente neo-operaista" ligada a nomes como Yann Moulier-Boutang, Carlo Vercellone e Maurizio

${ }^{2}$ Note-se que, nesse período, o trabalho (heterônomo) é, na óptica de Gorz, uma categoria historicamente específica, mas insuperável numa sociedade moderna complexa. 
Lazzarato - que coloca uma grande ênfase no conceito de "capitalismo cognitivo" (p. 256).

Na sociedade pós-industrial assiste-se, na perspectiva de Gorz, à constituição efetiva do "general intellect" de que Marx falava nos Grundrisse (p. 257). Hoje em dia predominam o "trabalho 'imaterial'" (p. 257) e a produção de "conhecimentos" (p. 258) que dificilmente são enclausuráveis na forma do valor mercantil. Em paralelo, a "contradição" entre a "criatividade" requerida por suas atividades e a exigência de uma "sujeição total da pessoa" (p. 259) conduz a "intelectualidade de massas" (p. 261) a rejeitar o estatuto de Eu S.A. híper-flexível e a colaborar na reivindicação do direito a "desenvolver atividades autodeterminadas" fora do mercado (p. 265).

Nos últimos cinco anos de vida (p. 275), André Gorz é bastante influenciado pela corrente de pensamento conhecida como "crítica do valor" e, principalmente, pelas obras de Moishe Postone e Robert Kurz (p. 273). Estes autores colocam o acento tónico no valor como forma universal de riqueza e de mediação social fetichista e "fundamentalmente destrutiva" (p. 275). Essa influência é particularmente visível em vários artigos redigidos nesse período e em Ecologica (2008), livro publicado a título póstumo. Gorz socorre-se de Kurz e Postone para operar "uma reformulação e uma atualização das suas próprias teses" (p. 273) que consiste amiúde numa "radicalização" das mesmas (p. 275).

Ao adotar a "crítica categorial" do filósofo social germânico (p. 274), Gorz consegue fundamentar de modo mais coerente sua teoria da crise (p. 270-271) e a desnaturalização das "abstrações reais" capitalistas, que constituem outras tantas formas de dominação impessoal (p. 274). É digno de nota que o autor já não se cinge a pugnar pela redução da jornada laboral ("heterônoma"); a emancipação exige agora a abolição do "trabalho enquanto forma de organização social" (p. 275), quer dizer, a sua transformação em "autoprodução" (p. 287) ou "autoatividade" (p. 288). Do mesmo modo, "já não se trata somente de limitar as trocas mercantis mas de aboli-las" (p. 292, itálico no original). 
O autor abandona o esquema da sociedade dual porque, enquanto o capital subsistir, não existe nenhuma esfera pretensamente autônoma suscetível de se eximir "à lógica da valorização" (p. 263). Assim, a derradeira "utopia" gorziana possui um cariz completamente "pós-mercantil" (p. 288). O comunismo requer a construção de "novas formas de socialidade baseadas na auto-organização coletiva" (p. 291) e a constituição de "um tempo livre carregado de sentido" para os indivíduos (p. 300).

Em jeito de balanço, pode-se afirmar que, em André Gorz: une philosophie de l'émancipation, Françoise Gollain identifica como núcleo duro do pensamento gorziano a "tensão entre heteronomia e exigência de autonomia" (p. 17). Nas palavras de Gollain, "a força-motriz da sua obra é (...) constituída pela contradição dinâmica entre a objetividade e a materialidade das estruturas econômicas, sociais e políticas, por um lado, e a subjetividade individual, por outro" (p. 17, itálico no original). De fato, o aspeto mais original da (re)interpretação gollainiana de André Gorz é provavelmente a tese de que "a sua obra retira (...) sua coerência profunda do seu substrato fenomenológico e existencialista" e, em especial, da "filosofia de Sartre" (p. 15). Do primeiro ao último livro, defende Gollain, "a exigência moral (...) de realização da liberdade" individual é uma presença constante (p. 18) sob a forma de "um apego à problemática do sujeito, da sua experiência de vida e da sua emancipação" (p. 19). A imagem que o leitor retém de Gorz é, portanto, a de um "intelectual comprometido (engagé) para quem a vocação contestatária e a vocação filosófica são indissociáveis" (p. 15) e para quem é possível "uma outra modernidade" pós-mercantil (p. 317).

São escassas as insuficiências que podem ser apontadas à pesquisa extraordinária de Françoise Gollain. Realço duas. Em primeiro lugar, embora efetue uma excelente contextualização intelectual da obra gorziana, Gollain dedica uma atenção reduzida à bibliografia secundária e, em particular, aos numerosos artigos críticos de vários aspetos da teoria de Gorz. Creio que um esforço adicional para incorporar parte dessa literatura teria 
permitido apresentar ao leitor a voz do contraditório. Em segundo lugar, apesar de serem mencionados, alguns aspetos biográficos cruciais para o desenvolvimento do pensamento de Gorz (a infância difícil, a relação com Doreen Keir, a profissão de jornalista etc.) são nitidamente subexplorados por Gollain. ${ }^{3}$ Não obstante essas pechas, o livro de Françoise Gollain constitui uma pesquisa portentosa que rivaliza com aquelas de Josué Pereira da Silva e de Willy Gianinazzi em termos de erudição, clareza e qualidade da escrita.

Nuno Miguel Cardoso Machado é Doutor em Sociologia Econômica e das Organizações e pesquisador no SOCIUS, Instituto Superior de Economia e Gestão, Universidade de Lisboa. $\triangle$ nuno.cocas.machado@gmail.com

\section{Referências}

1. BOWRING, Finn. André Gorz and the sartrean legacy: arguments for a personcentered social theory. Londres/Nova York: Macmillan/St. Martin's Press, 2000.

2. GIANINAZZI, Willy. André Gorz : une vie. Paris: Éditions La Découverte, 2016.

3. GOLLAIN, Françoise. André Gorz, une écologie à même le corps. EcoRev' Revue Critique d'Écologie Politique, n. 45, p. 63-70, 2017. https://doi.org/10.3917/ ecorev.045.0063

4. GOLLAIN, Françoise. André Gorz, vers l'inconditionnalité du revenu. L'Économie Politique, n. 67, p. 50-61, 2015. https://doi.org/10.3917/leco.067.0050

5. GOLLAIN, Françoise. André Gorz : pour une pensée de l'écosocialisme. Neuvyen-Champagne: Éditions le passager clandestin, 2014.

6. GOLLAIN, Françoise. André Gorz était-il un écologiste ? Écologie \& Politique, n. 44, p. 77-91, 2012. https://doi.org/10.3917/ecopo.044.0077

7. GOLLAIN, Françoise. L'apport d'André Gorz au débat sur le capitalisme cognitif. Revue du MAUSS, n. 35, p. 541-558, 2010. https://doi.org/10.3917/rdm.035.0541

8. GOLLAIN, Françoise. André Gorz, un marxiste existentialiste : I'histoire et le sujet de I'histoire. Revue du MAUSS, n. 34, p. 349-367, 2009. https://doi. org/10.3917/rdm.034.0349

\footnotetext{
${ }^{3}$ Neste aspeto, a obra de Gianinazzi (2016) é mais feliz. O autor conseguiu lançar uma nova luz sobre diversos aspetos da vida pessoal de André Gorz graças a entrevistas que realizou com colegas de escola, amigos e interlocutores intelectuais.
} 
9. GOLLAIN, Françoise. André, mon maître : hommage à André Gorz. Revue du MAUSS, n. 31, p. 545-557, 2008. https://doi.org/10.3917/rdm.031.0545

10. GOLLAIN, Françoise. Une critique du travail : entre écologie et socialisme. Paris: Éditions La Découverte, 2000.

11. LITTLE, Adrian. The political thought of André Gorz. 2. ed. Nova York: Routledge, 2013[1996].

12. LODZIAK, Conrad; TATMAN, Jeremy. André Gorz: a critical introduction. Londres/Chicago: Pluto Press, 1997.

13. SILVA, Josué Pereira da. Nota sobre o conceito de "reformas revolucionárias" de André Gorz. Caderno CRH, v. 30, n. 81, p. 507-521, 2017b. https://doi. org/10.1590/S0103-49792017000300008

14. SILVA, Josué P. da. Dez anos sem (com) André Gorz. Caderno CRH, v. 30, n. 81, p. 413-416, 2017a. https://doi.org/10.1590/S0103-49792017000300001

15. SILVA, Josué P. da. Tempo de trabalho e imaterialidade na teoria social de André Gorz. Caderno CRH, v. 27, n. 70, p. 101-113, 2014. https://doi.org/10.1590/ $\underline{\mathrm{S} 0103-49792014000100008}$

16. SILVA, Josué P. da. André Gorz e Renda Básica: uma história de conversão crítica. In: CONGRESSO INTERNACIONAL DA REDE MUNDIAL DE RENDA BÁSICA, 13., 2010, São Paulo. Anais [...]. Londres: BIEN, 2010. Disponível em: https://pt.scribd.com/document/481805821/Art\%C2\%BA-Andre-Gorz-e-RendaBasica-j-Pereira-Da-Silva

17. SILVA, Josué P. da. Tensão entre tempo social e tempo individual. Tempo Social, v. 21, n. 1, p. 35-50, 2009. https://doi.org/10.1590/S0103-20702009000100003

18. SILVA, Josué P. da. André Gorz: trabalho e política. São Paulo: Annablume, 2002.

Recebido: 27 out. 2020 Aceito: 26 jan. 2021 